\title{
Possibility of use adsorption chillers for increase efficiency in conventional power plant
}

\author{
Karol Sztekler ${ }^{1 *}$, Wojciech Kalawa ${ }^{1}$, Wojciech Nowak $^{1}$, Sebastian Stefański ${ }^{1}$, Jarosław Krzywański $^{2}$,Karolina \\ Grabowska $^{2}$ and Łukasz Mika ${ }^{1}$ \\ ${ }^{1}$ AGH University of Science and Technology, A. Mickiewicza Av. 30, 30-059 Krakow, Poland \\ ${ }^{2}$ Jan Dlugosz University, Armii Krajowej Av. 13/15, 42-200 Czestochowa, Poland
}

\begin{abstract}
Long-term forecasts indicate that the annual increases in electricity demand by 2030 will be approx. $2 \div 3 \%$ a year. At present, $40 \%$ of the world's electricity is produced using coal-fired power plants. Forecasts indicate that coal will still be the predominant fuel used to produce electricity and thus any actions aimed at increasing the efficiency of electricity production are purposeful. Enormous amounts of waste heat, which is not sufficiently used, are released during the process of electricity production. One of the ways to manage it is to use refrigeration systems based on adsorption chillers which would use waste heat to generate cold that would be employed for air-conditioning or process purposes. In this paper, the cycle of a conventional coal-fired power plant was modelled and then the possibilities of using waste heat for generation of cold as well as the impact of a chiller on the operation of a power unit were analysed using IPSEpro software.
\end{abstract}

\section{Introduction}

Technological development is closely related to energy production and conversion. Nowadays, energy in the form of heat, electricity or cold is necessary in almost every engineering process. Increasing energy demand and problems associated with excessive exploitation of the environment became a motivation to implement eco-friendly and cost-effective solutions. The use of renewable energy sources (RES) makes it possible to reduce the consumption of fossil fuels, which contributes to environmental pollution by, e.g. emissions of harmful substances into the air or waste water production. However, intensive work on renewable energy sources requires more and more advanced processes which require a supply of energy to be carried out. In addition to increasing the share of renewable energy sources, greater attention is paid to the manner and efficiency of energy use and the environmental impact of processes [1-3]. Approximately $60 \%$ of chemical energy of fuel in the process of electricity production is converted into heat which is dissipated into the environment in conventional power plants. The efficiency of use of non-renewable primary energy of fossil fuels can be increased by using combined heat and power generation whereby waste heat is managed for engineering processes, heating of buildings and preparation of domestic hot water as well as is stored until the demand for heat increases. In many cases, in conventional generating units, it is not possible to use the entire potential of heat dissipated into the environment, e.g. in regions near the tropics or in the summer season.

An increasing number of electronic systems and automation of processes contribute to the growing energy demand, both in terms of power supply to and cooling of equipment. With the development of technology, requirements regarding thermal comfort in buildings grow as well. According to 2018 data from the International Energy Agency [4], air-conditioning units account for approximately $10 \%$ of the global electricity consumption and makes up about $1 / 5$ of the demand for electricity in buildings. The demand for cooling power also results from the need to produce and store food. An increase in the world population, which will reach a figure of 10 billion by 2050 according to forecasts [5], contributes to a dynamic growth of the demand for heat, electricity and cold. As far as refrigeration equipment is concerned, compressor systems, whose technology was highly developed at the beginning of the 20th century, are clearly predominant. Due to their higher performance, compressor units became more popular and were developed faster than sorption technology [6]. A large share of compressor units and a rise in the demand for cold put the power system under heavy load. A high temperature is accompanied by a high demand for cold and a concurrent decrease in electricity production capacity in conventional power plants due to an increase in ambient temperature and low levels of cooling water tanks, which contributes to disturbances in the operation of power systems [7,8]. According to forecasts, electricity consumption in Poland is expected to increase from approximately $150 \mathrm{TWh}$ in 2015 to around 225 TWh in 2040 and then it will start to decrease [8]. At the same time, due to improving energy standards in the construction industry, the demand for heat does not increase together with the growing number of buildings. Forecasts indicate that the demand for district heating in Poland will drop by about $25 \%$ between 2025 and 2040

* Corresponding author: sztekler@agh.edu.pl 
[8]. This may affect the efficiency of energy production and the costs of electricity generation.

A problem related to population growth is also access to drinking water, which constitutes $0.5 \%$ of the world's water resources, the increase in the demand for drinking water being estimated at $55 \%$ by 2050 relative to 2000 [10]. This problem already affects many regions, e.g. the Middle East, Africa or Singapore. Those regions, due to their geographical location, generally also have a high solar energy use potential and a high demand for cold. An effective use of the solar energy potential is possible by employing polygeneration systems. The use of sorption refrigeration equipment powered by a stream of heat allows utilisation of excess and waste heat to generate cold. Sorption refrigeration systems can be divided into absorption (ABC) and adsorption (ADC) equipment. Implementation of adsorption chillers using water as a working medium enables water desalination and its treatment. In combination with the availability of heat, the efficiency of use of primary energy increases significantly and allows production of drinking water and cold.

\section{Adsorption chiller}

Sorption refrigeration equipment shows lower values of the coefficient of performance (COP) than compressor units. Moreover, $\mathrm{ABC}$ or $\mathrm{ADC}$ systems cannot replace compressor systems in low-temperature refrigeration plants, e.g. in freezers, due to limitations of properties of their media, i.e. evaporating temperatures and pressures [11]. Nevertheless, they show very important advantages such as the use of a low-temperature stream of heat as the powering energy, quiet operation without vibration and considerably less moving parts. Adsorption equipment is characterised by large dimensions and weight due to the amount of sorption material upon which the cooling capacity (CC) depends. However, $\mathrm{ADC}$ systems have a very important advantage, i.e. the ability to desalinate water (in the case of a circuit with water as the working medium). ADCs have a considerably lower required temperature of the powering heat source than absorption units, so it is possible to use them in the case of access to a lowtemperature source of waste heat or to increase the efficiency of CHP systems [6].

The principle of operation of an adsorption refrigeration system uses a closed or open working medium circuit, e.g. with water or ammonia. The phenomenon of physical adsorption is used, i.e. binding of molecules of the working medium (called adsorbate) by a solid material (adsorbent). The binding process (adsorption) is reversible, which can be achieved by changing the adsorbent temperature (TSA - temperature swing adsorption) or the pressure (PSA - pressure swing adsorption). Both processes are carried out alternately in the same part of a chiller called the adsorption bed. The design and method of connecting the parts of this system were shown schematically in Figure 1. In the case of $\mathrm{ADC}$ systems, under conditions of reduced pressure and at a low temperature (approx. $5-12^{\circ} \mathrm{C}$ ), the working medium warms up and evaporates in the evaporator, using the heat from an external circuit which is the cold sink. Next, medium vapours are fed onto the adsorption bed. Due to the alternately conducted process of adsorption and regeneration, in order to keep the continuity of operation, adsorption beds are duplicated. Thanks to this, phase-shifted beds ensure continuous system operation and constant generation of the cooling effect. Adsorbate molecules in the form of vapour are bound in the adsorbent placed in the bed which is accompanied by a release of heat. Continuous heat collection ensures bed temperature within the range of $20-40^{\circ} \mathrm{C}$ and makes the adsorption process possible. After adsorbing the maximum amount of medium vapour in given conditions, vapour supply is fed onto the second bed. In the next stage, the first bed undergoes desorption (regeneration) using a heat source with a temperature of $50-95^{\circ} \mathrm{C}$. Subsequently, the released medium vapour is fed into a condenser. The produced condensate is purified from substances dissolved in water feeding the evaporator (including salt) and can be fed into the evaporator again or discharged into a purified (desalinated) water tank. After switching the access of refrigerant vapour and heating/cooling circuits in the beds, another cycle of operation of the device starts.

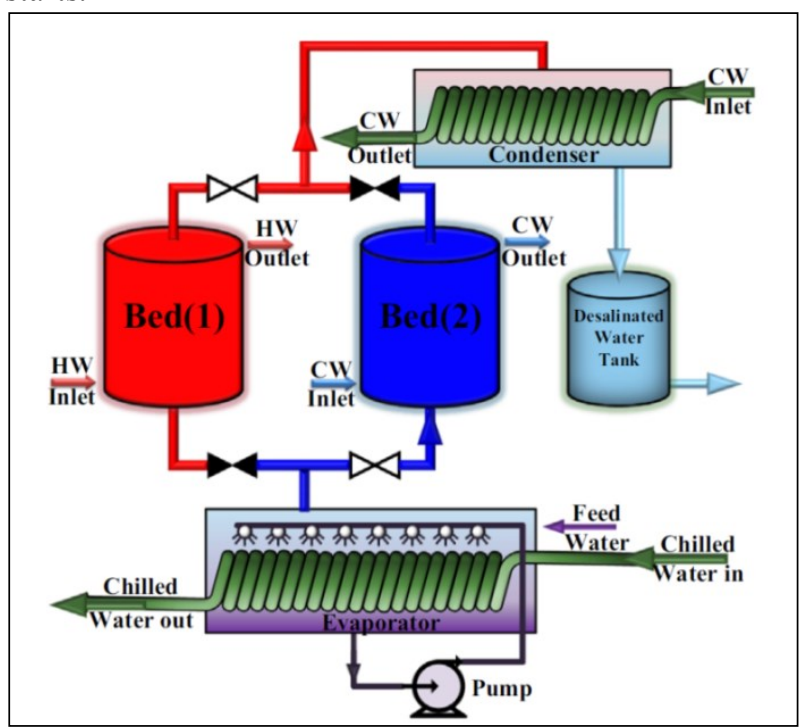

Fig. 1. Diagram of two-bed ADC system with desalination function [Chyba! Nenalezen zdroj odkazů.].

Beside $\mathrm{COP}$ and $\mathrm{CC}$, additional quality indicators are used to assess adsorption equipment. In the case of ADCs, attention is paid to the dimensions of a device which is described by means of the specific cooling power (SCP) indicator, i.e. cooling power per unit mass of dry adsorbent used in the device. In the case of equipment with a circuit allowing water desalination, specific daily water production (SDWP), expressed as the daily production of desalinated water relative to $1 \mathrm{~kg}$ of dry adsorbent, describes the amount of additional gain in the form of drinking water [6]. 


\section{Reference power plant cycle}

On the basis of data found in the Plans and Specifications of a $833 \mathrm{MW}$ power unit at BOT Elektrownia Bełchatów SA (Z-398, VOL. 3 of the environmental impact report drawn up by Energoprojekt Katowice S.A.), a thermal cycle model for Bełchatów Power Plant's power unit was developed, hereinafter referred to as the reference cycle. A reference model of a simulation cycle developed in such a manner makes it possible to obtain information on all its thermodynamic parameters and the amount of generated flue gases undergoing treatment to remove carbon dioxide. Basic data of the reference cycle operating at nominal load were included in the Table 1 below.

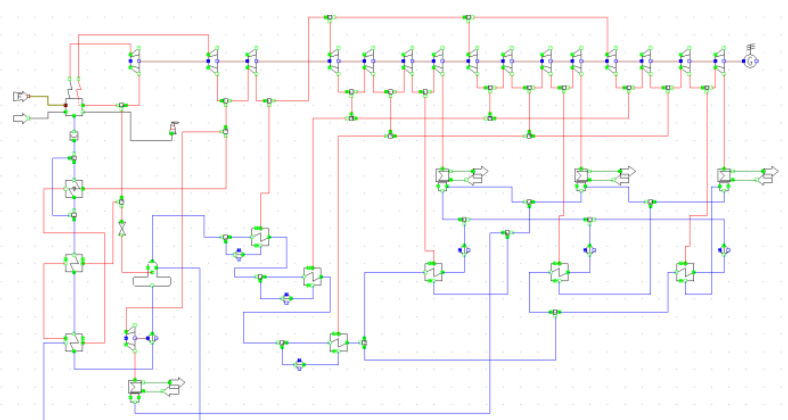

Fig. 1. Reference power unit cycle at Bełchatów Power Plant, 858 MWe.

Table 1. Technical data of Bełchatów Power Plant.

\begin{tabular}{|l|c|c|}
\hline \multicolumn{1}{|c|}{ Parameter } & Value & Unit \\
\hline Electrical power & 833 & $\mathrm{MW}$ \\
\hline Main steam pressure & 26.6 & $\mathrm{MPa}$ \\
\hline Main steam temperature & 554 & ${ }^{\circ} \mathrm{C}$ \\
\hline Main steam mass flow & 625 & $\mathrm{~kg} / \mathrm{s}$ \\
\hline Reheated steam pressure & 5.4 & $\mathrm{MPa}$ \\
\hline Reheated steam temperature & 582 & ${ }^{\circ} \mathrm{C}$ \\
\hline Reheated steam mass flow & 575 & $\mathrm{~kg} / \mathrm{s}$ \\
\hline Feed water temperature & 275 & ${ }^{\circ} \mathrm{C}$ \\
\hline $\begin{array}{l}\text { Fuel chemical energy utilisation factor } \\
\text { (EUF) [.... }\end{array}$ & 45.1 & $\%$ \\
\hline Flue gas flow & 1019 & $\mathrm{~kg} / \mathrm{s}$ \\
\hline Fuel consumption & 237 & $\mathrm{~kg} / \mathrm{s}$ \\
\hline
\end{tabular}

On the basis of a simulation analysis of operation of the power unit as well as of a thorough analysis of its operation, one can conclude that only flue gases leaving the power unit have sufficiently high temperature that it is possible to use them for cold production by using adsorption chillers.

\section{Adsorption chiller}

BryAir refrigeration unit, model: ADC Series F-RAME F-330, were chosen for the model analysis. It can work at supply temperatures in the range from $52^{\circ} \mathrm{C}$ to $93^{\circ} \mathrm{C}$, producing ice water with a temperature of $7.2^{\circ} \mathrm{C}$. A drop in the temperature of water feeding the chiller (difference between inlet water temperature and water exiting the chiller) specified in the technical specification of the model is $\Delta \mathrm{Tz}=6.6^{\circ} \mathrm{C}$. Power consumption is small: $1.3-2.4 \mathrm{~kW}$.

Table 2. Technical specification of BryAir chiller ADC Series F-FRAME F-330 [12].

\begin{tabular}{|l|c|}
\hline Cooling capacity & $1.191 \mathrm{~kW}$ \\
\hline Electricity consumption & $1.3-2.4 \mathrm{~kW}$ \\
\hline Refrigerant type & Water \\
\hline Chilled water inlet temperature & $12.8^{\circ} \mathrm{C}$ \\
\hline Chilled water outlet temperature & $7.2^{\circ} \mathrm{C}$ \\
\hline Condenser water inlet temperature & $29^{\circ} \mathrm{C}$ \\
\hline Condenser water outlet temperature & $35^{\circ} \mathrm{C}$ \\
\hline Hot water inlet temperature & $90.6^{\circ} \mathrm{C}$ \\
\hline Hot water outlet temperature & $84^{\circ} \mathrm{C}$ \\
\hline Hot water for regeneration temperature range & $52^{\circ} \mathrm{C}-93^{\circ} \mathrm{C}$ \\
\hline Temperature drop for regeneration process & $\Delta \mathrm{t}=6.6^{\circ} \mathrm{C}$ \\
\hline
\end{tabular}

The value of the coefficient of performance of a chiller using the silica gel-water system is variable and strongly dependent on the temperature of feed water. On the basis of the diagram from Fig. 2, the COP value for hot water temperature of $90.6{ }^{\circ} \mathrm{C}$ is $\mathrm{COP}_{90.6^{\circ} \mathrm{C}}=0.5$ while, at the temperature of $52^{\circ} \mathrm{C}$, this value is $\mathrm{COP}_{52^{\circ} \mathrm{C}}=0.28$.

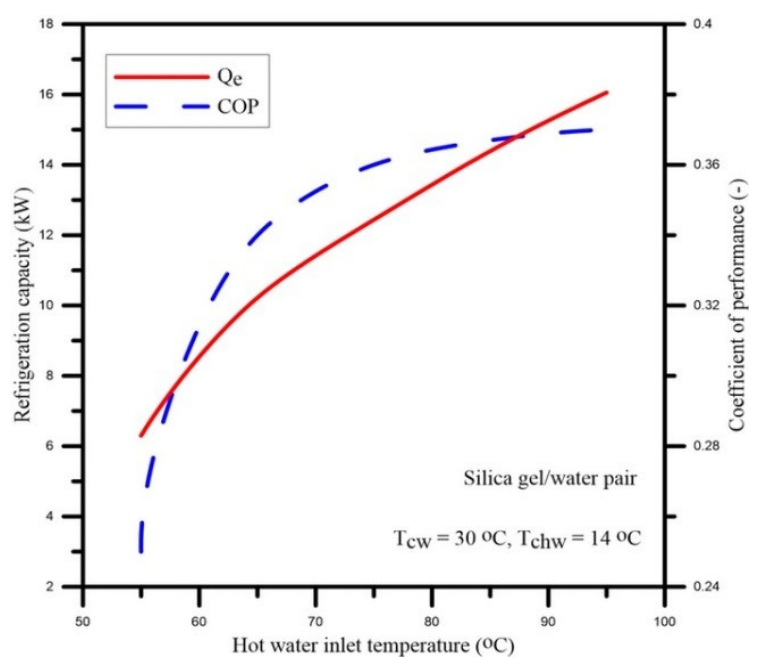

Fig. 2. COP values of a silica gel - water chiller depending on the temperature of feed water [13].

Adsorption chillers can work in systems where the temperature of water necessary for the regeneration process is $52^{\circ} \mathrm{C}$. According to the literature, a refrigeration system can operate at a temperature below $50^{\circ} \mathrm{C}$. This type of device is used wherever it is possible to use heat with parameters lower than $50^{\circ} \mathrm{C}$. In this article, the use of a chiller to recover heat from flue gas was considered. The refrigerator model in IPSEpro 
software was described by equations of mass and energy balance.

What is used for the bed regeneration process is hot water with a temperature of $90.6^{\circ} \mathrm{C}$, produced in the heat exchanger (1) fed with flue gases with a temperature of $170^{\circ} \mathrm{C}$, which are cooled down to a temperature of $95^{\circ} \mathrm{C}$. Water used to condense steam in the condenser and collect heat from the bed (adsorption process) trimmed during adsorption in a chiller circulates in an external circuit and is cooled down in an air-cooled condenser. A diagram of the thermal cycle of a conventional power plant along with the installed adsorption chiller was shown in Figure 3.

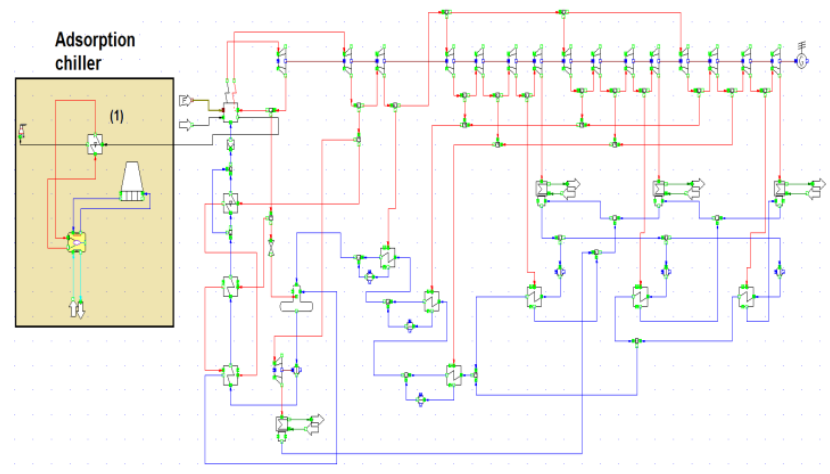

Fig. 3. Power plant integrated with adsorption chiller.

Table 3. Summary of the most important data

\begin{tabular}{|l|c|c|c|c|}
\hline \multicolumn{1}{|c|}{ Name of parameter } & Symbol & Value & Value & Unit \\
\hline $\begin{array}{l}\text { Temperature water for } \\
\text { regeneration process }\end{array}$ & $\mathrm{T}_{\mathrm{z}}$ & 90.6 & 52 & ${ }^{\circ} \mathrm{C}$ \\
\hline Electrical capacity & $\mathrm{N}_{\mathrm{el}}$ & 833 & 833 & $\mathrm{MW}$ \\
\hline $\begin{array}{l}\text { Maximum heat influx into } \\
\text { the adsorption chiller }\end{array}$ & $\dot{\mathrm{Q}}_{\mathrm{z}}$ & 90.1 & 90.1 & $\mathrm{MW}$ \\
\hline Maximum cooling capacity & $\dot{\mathrm{Q}}_{\mathrm{ch}}$ & 45.05 & 25.2 & $\mathrm{MW}$ \\
\hline $\begin{array}{l}\text { COP (Coefficient Of } \\
\text { Performance) Bry Air chiller } \\
\text { ADC }\end{array}$ & $\mathrm{COP}$ & 0.5 & 0.28 & - \\
\hline $\begin{array}{l}\text { EUF } \\
\text { (indicator of chemical } \\
\text { energy use of fuel in the } \\
\text { cogenertaion system) }\end{array}$ & $\mathrm{EUF}_{\mathrm{T}}$ & 52.3 & 51 & $\%$ \\
\hline $\begin{array}{l}\text { District water temperature } \\
\text { drop in the chiller }\end{array}$ & $\Delta \mathrm{T}_{\mathrm{z}}$ & 6.6 & 6.6 & ${ }^{\circ} \mathrm{C}$ \\
\hline $\begin{array}{l}\text { District water mass flow for } \\
\text { ADC }\end{array}$ & $\dot{\mathrm{m}}$ & 1,293 & 3,267 & $\mathrm{~kg} / \mathrm{s}$ \\
\hline
\end{tabular}

\section{Summary}

The main purpose of this paper was to analyse the effect of use of adsorption chillers on the increase of utilisation of the chemical energy of fuel. As a result of use of refrigeration and cold production systems, a 7.2\% (at $\mathrm{T}_{\mathrm{z}}=90.6^{\circ} \mathrm{C}$ ) and $5.9 \%\left(\right.$ at $\mathrm{T}_{\mathrm{z}}=52^{\circ} \mathrm{C}$ ) increase in the use of chemical energy of fuel occurs compared to the base system where only electricity is produced. Trigeneration and cogeneration systems have a significant impact on the reduction of losses associated with production of electricity. In the analysed case, the use of adsorption chillers has a positive effect on the power unit's operation and results in more efficient use of the chemical energy of fuel. The generated cold in the amount of 45.05 MW and 25.2 MW can be later used for process purposes, thus generating an additional profit associated with the sale of a product which is cold. Adsorption refrigeration systems are used more and more and, in combination with renewable energy sources, they can be a cheap source of cold. Combining an adsorption chiller with a conventional power plant system makes it possible to use waste heat, which is becoming more and more important due to the changing market demand for heat and cold.

\section{References}

1. Kyoto Protocol to the United Nations Framework Convention on Climate Change (1997)

2. Directive 2009/125/EC of the European Parilament and of the Council of 21 October 2009 establishing a framework for the setting of ecodesign requirements for energy-related products OJ L 285

3. Directive 2012/27/EU of the European Parliament and of the Council of 25 October 2012 on energy efficiency, amending Directives 2009/125/EC and 2010/30/EU and repealing Directives 2004/8/EC and 2006/32/EC OJ L 315

4. IEA, The Future of Cooling: Opportunities for energy-efficient air conditioning (2018)

5. Department of Economic and Social Affairs, Population Division 2015 World Population Prospects: The 2015 Revision, Key Findings and Advance Tables (New York: United Nations)

6. R. Z. Wang, L. Wang, J. Wu, Adsorption refrigeration technology: theory and application (John Wiley \& Sons Inc, New York, 2014)

7. Press Office of PSE S.A., Announcement from 10 August 2015, https://www.pse.pl/biuro-prasowe/ aktualnosci (in Polish)

8. Press Office of PSE S.A., Announcement from 26 June 2006, https://www.pse.pl/biuro-prasowe/ aktualnosci (in Polish)

9. Polish Ministry of the Economy, Attachment 2. to Energy Policy in Poland until 2050: «Conclusions from the forecast for the Polish Energy Policy until 2050» (in Polish: «Wnioski z analiz prognostycznych na potrzeby Polityki energetycznej Polski do 2050 roku») Warsaw (2015)

10. OECD 2012 Environmental Outlook to 2050, OECD Publishing

11. C.A. Balaras, G. Grossman, H.M. Henning, C.A. Infante Ferreira, Erich Podesser, L. Wang, E. Wiemken, Renew. Sust. Energ Rev. 11 299-314 (2007)

12. Technical data, https://www.bryair.com/productssolutions/adsorption-chillers

13. M.G. Gado, et al., Parametric study of an adsorption refrigeration system using different working pairs, Proc., 17th Int. Conf. on Aerospace Sciences \& Aviation Tech. (Cairo, Egypt, 2017) 